Int. J. Dev. Biol. 49: 117-124 (2005)

doi: $10.1387 / \mathrm{ijdb} .041934 \mathrm{eb}$

\title{
Brain switching: studying evolutionary behavioral changes in the context of individual brain development
}

\author{
EVAN BALABAN* \\ Behavioral Neuroscience Program, McGill University, Montreal, Canada
}

\begin{abstract}
Working together at Nogent, Marie-Aimee Teillet, Nicole Le Douarin and the author successfully developed an extension of the quail-chick transplant technique for relating species brain cell differences to behavioral differences. This article reviews the application of the technique to species differences in motor behavior (crowing) and auditory perceptual preferences. Interspecies brain transplants provide a unique means for elucidating general cellular mechanisms which integrate evolutionary and individual experience during the development of complex brain circuitry.
\end{abstract}

KEY WORDS: brain transplant, chimera, predisposition, vocalization, auditory perception

The effects of tissue transplants on behavior have been the stuff of fiction and fantasy for at least the past 185 years, running the gamut from Mary Wollstonecraft Shelley's (1818) «Frankenstein, or The Modern Prometheus», through H.G. Wells' (1896) «The Island of Dr. Moreau» to a satiric modern cinematic relative, Mel Brooks' (1974) «Young Frankenstein» [WARNING! DO NOT TAKE THIS BRAIN! ABNORMAL!]. During the course of the $20^{\text {th }}$ century, many investigators have independently performed transplants of presumptive neural material between different embryos of the same or different vertebrate species, but few did so for the purpose of studying the behavioral effects of transplants. For instance, Petar Martinovitch (Martinovitch 1957, 1958, 1959; Martinovitch \& Pavlovic 1958) appears to have been the first person to successfully perform intra- and inter-species head (including brain) transplants with birds, but few of these animals survived hatching; Seno and Saito (1959) also reported a substitution of a chick head onto a duck embryo. However, Heaton (1973) transplanted eyes between chickens and bobwhite quail (Colinus virginiacus) [quail eyes were connected with the chicken brain and late embryos exhibited pupillary responses to light, but none of these animals were able to hatch] and Sohal (1976) examined the effects of reciprocal transplantation of the forebrain primordium between chick and duck embryos on embryonic motility and hatching behavior [motility was unaffected but hatching time followed forebrain species identity].

In the early 1960s, John E. Swisher attempted switching embryonic brains between salamanders and frogs (personal communication) to study the development of behavioral differences between these species without much success. In a 1963 interview he gave to a reporter from the National Observer, Swisher described his interests in transferring «habits» between animal species:

The experiments may cause some strange behavior in the animal world. «Salamander tadpoles eat meat, but frog tadpoles eat algae and other small plant life,» Mr. Swisher explains. «Suppose you have a mouth and body adapted to eating vegetables and a brain that doesn't want to do anything but chase animals around?» [William Tucker, «Some delicate surgery will transpose brains», National Observer, 23 September 1963].

Paul Pietsch (1972a,b; 1981) published informal reports of larval brain transplants in amphibians, removing «developed» larval brains from the host animal and replacing them with the developed larval brain of a donor, with function presumably restored when the donor brain regenerated its connections with the host nervous and circulatory systems. He described 5 brain transplants (whole brain anterior to the cervical spinal cord) between donor marbled salamanders (Amblystoma opacum) and host larval tiger salamanders (Amblystoma tigrinum) and 12 brain transplants (whole brain anterior to the medulla) from frog tadpole (Rana pipiens) donors to salamander (Amblystoma punctatum) larval hosts. Pietsch reported that the whole-brain transplants between the two salamander species resulted in animals that «behaved in a manner indistinguishable from unoperated, normal control animals». Like Swisher, Pietsch was interested in the feeding behavior of the frog-donor, salamander host embryos, since the brain of the algae-eating tadpole was now in the body of the carnivorous salamander. Pietsch reported that 8 of the 12 transplants «never regained consciousness» (although they «lived for months»), while 4 of the transplants, which exhibited the ability to stand and swim, would inspect worms that normally elicited

\footnotetext{
*Address correspondence to: Dr. Evan Balaban. Behavioral Neuroscience Program, McGill University, 1205 Avenue Dr. Penfield, Montreal, Canada H3A 1B1 . Fax: +1-514-398-4896. e-mail: evan@psych.mcgill.ca
} 
voracious salamander feeding behavior, but never tried to feed on them (or apparently anything else), even after more than two months of daily exposure to worms. These animals had to be kept alive by force-feeding. Control transplants of the same brain regions between two salamander larvae were reported to result in the return of normal feeding behavior after about three weeks. Pietsch also reported that an undisclosed number of frog-donor, salamander-host animals with transplants limited to the cerebral hemispheres exhibited normal salamander feeding behavior.

\section{What is the point of embryonic brain transplants?}

Given this background of negative popular culture and abortive or incomplete experimental success with the technique, why would anyone in their right mind want to become a brain-switcher? Now that neural transplants are routinely regarded as possible therapies for diseased and/or damaged brains that are fully formed, the notion of performing neural transplants between embryos with no therapeutic potential may appear quaint. Why pursue a technology that lacks the conceptual precision of single gene manipulations and why use transplants to study something as messy and ill-specified as behavioral development?

Studies relating neural development to behavior have reached a kind of crossroads. Recent advances in our understanding of cell signaling during development and the changes in gene expression that mediate the functional ontogeny of local brain regions have done much to demystify the processes of brain differentiation that occur in advance of behavior. Studies on map formation, axonal selection of targets, circuit activity dependence and plasticity have similarly shed light on the kinds of local dynamics that underlie the brain's developmental fine tuning and permanent plastic capacities. What is lacking is a good mechanistic understanding of the kind of organizational principles that relate local properties to more global aspects of behavioral circuit formation and function (Katz \& Harris-Warrick 1999). Any neural circuit governing even the most mundane behavior requires the spatial and temporal coordination of diverse cell groups distributed over broad regions of the nervous system. How is it that these distributed cellular elements are recruited into functional circuits in the first place? Are circuits assembled from the inside out, with local areas each developing their particular patterns of connectivity intrinsically and then forming their extrinsic connections, or from the outside in, with an initial sparse scaffolding of extrinsic connections playing an essential role in the formation of local intrinsic circuit properties? How is it that circuits develop the proper patterning of excitatory and inhibitory connections - are each developed independently (if so in what order?), or do they develop at the same time and influence each other? How do the various modulatory inputs to circuits develop - are they added on after circuits develop their basic functionality, or are they part of nascent circuits from the beginning, helping to sculpt out the development of more global circuit properties?

The pursuit of such questions is problematic because of the difficulty of defining what a neural circuit underlying a particular behavior consists of globally, especially when the cells that should be included in this circuit may change their identity over developmental time. For instance, in classical «inductive» interactions, signals exchanged between two cell types early in development have a big influence on the future properties of at least one of these types (as in the classic example of neural induction discovered by Mangold and Spemann). The effects of these early interactions may not become manifest until later in development, when the two cell types no longer have much to do with each other spatially or functionally. We know that many connections in the early nervous system are transient, but we do not know which of these fleeting contacts may or may not have importance for future behavioral circuit properties because we have no a-priori way of identifying the major players that organize circuit formation. Trying to understand development by working backwards from developed circuits may fail to reveal many aspects of the developmental process.

The combination of pre-existing (evolved) differences in functional brain circuitry provided by closely-related species that perform analogous behaviors differently, together with the ability to substitute developing cell groups within the brain, provides a unique screening method for mechanistic questions about global circuit formation that currently cannot be studied by any other means, including the manipulation of single genes. With reference to classical «induction» experiments, transplants are used to survey the central nervous system for cell groups that functionally transform the output of particular developed behavioral circuits. A change in behavior from host-type to donor-type resulting from the substitution of cells in a particular brain region indicates some developmentally important process for circuit organization and/or function emanating from that brain region. In the past, it would have been hard for researchers to know how to proceed once they found such regions. Today, the blending of transplant technology with modern techniques for analyzing local circuitry and noninvasive imaging methods for examining the role that local neural populations play in more global circuits offers the hope of discovering some of the basic principles through which global behavioral circuit organization emerges during development.

\section{Making brain switching reliable}

The initial transplant work on bird and amphibian embryos was not very satisfactory for behavioral studies, as the techniques had primarily been designed without the long-term survival of the subjects in mind. More refined surgical techniques for producing neural chimeras between two bird species, the domestic chicken and the Japanese quail, were successfully developed by Nicole Le Douarin and her colleagues subsequent to the discovery of the quail-chick cell marker and employed in their studies of the differentiation of the neural crest during embryogenesis (Le Douarin 1969, 1982, 1986, 1988; Le Douarin, Teillet \& FontainePerus 1984; LeDouarin et al., 1997; Le Douarin \& Kalcheim 1999; Teillet et al., 1999; Le Douarin et al., 2000). In the bulk of these experiments, chimeric animals were sacrificed for examination before hatching. However, it was known that animals with chimeric spinal cords were capable of hatching (Kinutani and Le Douarin 1985; Le Douarin 1986; Kinutani et al., 1986) and Marie-Aimee Teillet had been able to produce hatched animals carrying small transplants of the brain. In our subsequent work, we tried to better optimize the surgical techniques and found that we could also produce viable chimeras containing transplants of larger regions of the presumptive brain whose species-specific behaviors were transformed to the donor form of the behavior (Balaban, Teillet \& Le Douarin 1988). Control transplants of identical regions between 
two individual chickens did not show any behavioral changes. Continued work in my own laboratory (Balaban 1990, 1994, 1997; Gahr \& Balaban 1996; Long, Kennedy \& Balaban 2001) substantially refined these transplant techniques and made the production of chimeras with transplants ranging from a few cells to a whole brain feasible and reliable.

The key to producing reliable chimeras involves a combination of factors. First, it is best to use eggs within several days of laying that have been kept at about $17^{\circ} \mathrm{C}$ on a mechanical egg-turner. Minimizing the amount of transport of the pre-incubated eggs also helps. Second, there is an enormous loss of humidity from the egg during surgery; and it is very hard to visually keep track of drying on top of the exposed embryo. Performing the operations under conditions of high humidity, making as small a hole in the shell as possible to perform surgeries through and keeping the eggs heated from underneath by means of a glass-bead heater all lead to improvements in survival. Third, it is important to take great care with the manner of introduction and the temperature of the contrasting substance injected under the blastoderm to visualize the embryo. Fourth, the manufacture of surgical tools from stainless steel needles or wire frequently leads to the tool becoming slightly magnetized or to the buildup of static charges that cause retention of microscopic flakes of metal and other debris on the blade that can be left behind during surgery. Frequent cleaning of the knives with a solution of $\mathrm{NaOH}$, followed by light sonication, followed by rinses in sterile physiological solution, improve surgical survival. Fifth, it is best to seal the hole in the egg with sterile wound closure adhesive tapes that respire to prevent drops of moisture from accumulating during subsequent incubation; humidity must be rigorously regulated within the incubator within appropriate limits and increased several days before hatching. Finally, subsequent to the surgeries, it makes a big difference if the eggs are incubated with turning - this can be accomplished by mechanically modifying the incubator to turn the eggs through a smaller angle, so that the embryos do not come in contact with the hole in the shell or the material closing it.

\section{Choice of behavior, choice of questions}

Brain switching can be used to answer a number of questions about neural development. One type of question involves a more precise understanding of complex differences between normal and congenitally abnormal brains. Marie-Aimee Teillet, Nicole Le Douarin, Cesira Batini, Robert Naquet and their collaborators have examined the developmental locus of origin for epileptic seizures using transplants between chickens from an epileptogenic strain and from a normal strain (Teillet et al., 1993, Guy et al., 1995, Teillet et al., 1995, Fadlallah et al., 1995, Batini et al., 1996 Batini et al., 2004). Another type of question examines the developmental origin of sex differences in particular brain circuits, classically thought to be due to the hormonal environment that brain cells experience during circuit differentiation. Manfred Gahr (2003) has used intraspecies forebrain transplants between the two sexes of Japanese quail before sexual differentiation occurs, together with embryonic hormonal assays and DNA-based detection of the genetic sex of cells. He was specifically interested in screening for brain regions that affect sexual behavior independently of the hormonal environment that the brain regions develop in. The hormonal assays confirmed that the transplants did not appear to affect the hormonal environment of male and female host embryos during incubation. As adults, male individuals with a female forebrain can perform male-appropriate behaviors such as crowing, but appear to have a problem with regulation of gonadotropin-releasing hormone ( $\mathrm{GnRh}$ ) signaling in adulthood, resulting in regressed testes under photoperiodic conditions that normally stimulate gonadal recrudescence. These individuals show no interest in initiating copulatory behavior, even when placed for prolonged periods with receptive females. Females with male brains had normal female sexual behavior and gonadal function. Gahr hypothesizes that this difference is due to sex intrinsic differences in developmental levels of aromatase enzymes, used to produce estrogen within brain cells that will form part of the hypothalamic-pituitary-gonadal signaling axis. Males and females require different levels of $\mathrm{GnRh}$ output to maintain gonadal steroid production, with females having lower signaling levels than males. The intersex female donor, male host forebrain transplant results in a male with a $\mathrm{GnRh}$ signaling level of a female, which is too low to support adequate steroid production by an adult male testis. The identity of the relevant brain regions, their presumed difference in embryonic aromatase levels and the role these play in setting appropriate $\mathrm{GnRh}$ circuit output remains to be more exactly elucidated using more localized transplants.

In the case of epilepsy, transplants were used to ask whether epileptogenesis is a property of molecular changes restricted to particular local cell populations or even particular brain regions, or simply the result of having a certain minimum number of epileptogenic cells in any particular brain region. This is an excellent example of the power of transplants to address «population» properties of brain function that would be difficult to manipulate in such a controlled fashion with other methods. In the sex difference case, transplants successfully identified a subtle functional difference resulting from a cell-intrinsic difference presumably restricted to a particular cell population. This is an excellent example of the ability of the transplantation technique to uncover discrete developmental differences in local cell populations that result in major functional differences at the global level.

Work on species differences combines these two strengths of the transplant technique to simultaneously ask about «population» and «local» differences in cell interaction or function during development that underlie complex behavioral differences between species. We have used differences in a complex communicative motor behavior (the singing or "crowing» of male chickens and quail) to validate certain aspects of the chimera technique with respect to behavior before applying the technique to an important domain of behavioral development where little is known about organizing mechanisms - the question of perceptual predispositions.

\section{Validating behavioral studies by transferring patterns of motor behavior between species}

We chose to validate the chimera technique using male singing («crowing») behavior for three principal reasons. Crowing is a unique vocalization combined with a unique postural gesture of the head and neck in both quails and chicks. It requires complex motor coordination with respect to respiration, sound production and head movement and is acoustically and posturally distinct from all other vocalizations and behaviors in both species. It is 
also easy to rigorously quantify both the acoustical and gestural aspects of crowing. Second, while each individual in each species has an individually distinctive crowing vocalization, its structure is highly repeatable within each individual. The crows of all individuals within a species share a complex set of features that differentiate each one from all crows of the other species in exactly the same ways. Third, although crowing is normally part of adult male sexual behavior, it can be reliably elicited within a short time after hatching by administering the steroid hormone testosterone. This causes male and female chickens and quail to begin crowing within a day or two of hatching; testosterone induced crows of the two sexes within each species are identical. The modulation of this vocalization by testosterone represents a conditional physiological variable that is «equalized» by the hormone implant.

At the developmental stage when the transplants are performed, the brain identity of cells has already been specified, as well as some aspects of dorsoventral and segmental identity. However, specification of final cell type or of the neural circuit that cells will be a part of has almost certainly not yet taken place. The first question to answer was whether the «chicken-ness» or "quailness» of cells already matters for subsequent neural circuit development. Two kinds of results are possible. First, a population of quail cells put in a chicken brain could be influenced by the «chicken-ness» of surrounding cells, or these particular cells could be functionally identical in chicks and quail, resulting in no behavioral change of the host animal - the quail cells would end up supporting a chicken phenotype in the output of the circuit. Or, in a second scenario, the «quail-ness» of the transplanted cells could either «convert» chicken cells to support a quail phenotype, or could simply intrinsically express functional differences that are passively carried by chicken parts of a circuit, resulting in developed circuits that express some aspect of donor-type behavior in this individual host animal. There is a third possibility, that these surgeries simply produce a dysfunctional result either because they are equivalent to lesions, or because the interspecies cell mixture results in dysfunctional circuits. There are several checks on this possibility: control surgeries are performed between two normal members of the same species to see if the surgery has disruptive effects; since the transplants are done between two species with marked differences in the form of a behavior that can be rigorously quantified, the difference between a disruption and the transfer of a «normal» attribute from the other species is easy to discern.

Our initial work (Balaban et al., 1988) suggested that some form of the second scenario appeared to be operating. Transplants from quail donors into chicken hosts containing the caudal part of the midbrain transformed the temporal pattern of singing from chicken-like to quail-like. [Size differences between chickens (large head) and quail (small head) and the retention of original brain size of transplanted areas dictate the fact that with the relatively «large» transplants used here, reverse transplants (chick into quail) are not useful (a big brain in a small skull becomes compressed and the animals do not survive). In general, the experimental strategy is to start with large transplants and subsequently winnow them to smaller sizes- at small sizes reciprocal experiments can be done]. Transplants of other brain regions, such as the forebrain, were without effect on the bird's singing behavior (although we, like Sohal 1976, did see indications that forebrain transplants affect the timing of hatching behavior (unpublished observations)). We were struck by the apparent ability of quail cells to differentiate in a chick host and produce a brain that can function relatively normally. In the absence of transplants like the ones used in these experiments, embryos with these brain regions deleted die. Examination of the brains of chimeric animals revealed «normal» morphology, with chicken and quail regions apparently seamlessly interconnected. These initial experiments seemed to indicate that sound production, but not other aspects of this multidimensional behavior such as head movement patterns, were changed by midbrain transplants. Was this because species differences in the motor patterning of this unified behavioral performance were actually controlled by separate evolutionary changes to different brain regions?

\section{One behavior involving many regions equals multiple evolutionary changes}

To study this in more detail, we used transplants to examine the relationship between vocalization and the unique postural movements of the head and neck that characterize the crowing performance. This required a methodology for precisely measuring head and neck movements during crowing, which was provided by a manufacturer of video missile tracking systems looking for peaceful applications for their sophisticated military technology. This technology proved to be perfect for quantifying patterns of head and neck movements in real time in three dimensions without having to disturb the animals.

These experiments revealed that the species differences in head movement patterns during crowing could be transplanted completely independently of the acoustic signal (Balaban 1997). Transplants that conferred the head movement change were confined to a circumscribed region in the back portion of the brainstem, in a region containing premotor and motor areas controlling the extrinsic neck musculature. The identification of this region was facilitated by the extremely different pattern of head movement exhibited by chickens and quails during crowing. Chickens bring their head up and forward immediately prior to sound emission, but once their head is so positioned, they do not move it up and down, but rather keep it steady throughout sound production. Quail have a stereotyped sequence of exaggerated up and down head movements that start immediately before sound production begins and that are temporally locked to amplitude and frequency modulations in acoustic output. The head movements of individual quail are performed with little timing variation from performance to performance; while the fine details of the timing vary between individuals, there is a very characteristic temporal sequence shared by all quail.

Four details of the behavior of these chimeric animals are worth underlining. First, in each individual, the quail-like head movement was perfectly temporally integrated with the (chicken-like) acoustic output to form a completely unified behavioral performance. All chimeric animals exhibited acoustic patterns definitively within the range of variation of normal chickens. Second, the quail-like head movement pattern (which in normal quail is not given during any other vocalization, or in any other behavioral context in which the head is moved, including eating, drinking and yawning) was only produced in the context of crowing. For instance, in normal chickens and quails, head movement during yawning is identical and shows a pattern generally similar to the one shown by crowing 
chickens (except that the neck is not maintained in an extended position for as long a period of time). If transplantation had resulted in some abnormal function of brainstem circuits in chimeras, we might expect the «up and down» pattern of movements characteristic of quail crowing to show up during yawning or other types of head movements. This was carefully measured in all chimeric animals and yawns, eating, drinking and head movement during other vocalizations were all unaffected by the transplants. This is interesting in view of the fact that the cells in the transplant were located in premotor and motor control nuclei of the extrinsic neck muscles that should be active during all of these types of movement. As in «normal» quail, which otherwise produce head movements similar to chickens during eating, drinking, yawning and other vocalizations, the circuits in these chimeric animals appear to have a «quail crowing mode» that only gets turned on in the context of crowing, even though the signals for the crowing context presumably come from chicken regions of the brain and the acoustic signal production that accompanies the head movements has a chicken phenotype.

Third, normal chicken and quail vocalizations have different durations in different individuals and the duration of sound production and head movement is tightly correlated. This same feature is seen in chimeras- animals with shorter crows have correspondingly shorter durations of head movement than animals with longer crows. Thus, the (chicken-like) sound production circuitry and the (quail-like) head movement circuitry are either coordinating with each other, or both respond identically to a «timing signal» imposed by other cell groups, presumably of chick origin. Subsequent experiments by Brian Shaw (Shaw 1999, Shaw \& Kennedy 2002) have examined the coupling of head movement and sound production at the level of the midbrain and the anatomical features of projections connecting midbrain areas to brainstem premotor and motor regions within the areas covered by these transplants.

Finally, these experiments included transplants that varied in their rostrocaudal location within the effective area of the brainstem for transplanting quail crowing head movements. Analysis of the head movement pattern of chimeras revealed a correlation between the rostrocaudal location of the transplant and the point in the temporal head movement sequence where chimeras would begin their crowing head movements. Normal quail usually start the sequence with two slow up-and-down head movements of longer duration with spaces between them and finish with multiple up and down movements delivered in a rapid and continuous fashion. Chimeras with transplants including more caudal brainstem regions would start their head movement sequence with the slow «initial» up and down movements of normal quail; chimeras with transplants that began more rostrally started the head movement sequence with the faster, continuous head movements.

At a minimum, these experiments demonstrated the complete functional integration of transplanted cells into behavioral circuitry in the host brain (otherwise, the precise donor-specific patterns could not be preserved), as well as the specificity of behavioral effects to particular transplanted brain regions (otherwise, two unified aspects of a single behavior could not be transformed independently). Besides providing validation for these important basic features of transplants on behavior, this work also demonstrated the exceptional level of detail that appropriately quantified behavioral work on transplanted animals can provide, as well as providing some new insights into evolutionary mechanisms underlying this species behavioral difference.

Changes in complex motor sequences like those underlying the head movement and acoustic differences in quail and chick crowing were commonly believed to result from changes to higher-order motor control areas thought to assemble minimal gestural units into longer movement sequences. The expectation would have been that changes to some area common to sound production and head movement (perhaps in the forebrain or upper midbrain) should have accounted for the evolved differences between the two species, rather than the distributed pattern of changes found in transplant work. The «division of labor» between sound production and head movement areas that are clearly tied together by common timing signals and the correlation between the anatomical location of transplants and the part of the temporal movement sequence they transfer also provided new information on the functional organization of this complex multimodal behavior.

\section{Applying transplants to perceptual biases / predispositions}

I came to Nogent with a strong interest in using chimeras for studying perceptual predispositions, which I inherited from one of my doctoral advisors, Peter Marler (Marler \& Peters 1977, Marler et al., 1980, Marler 1984, 1990, 1997). Marler had found that young songbirds of two related species (the Song Sparrow Melospiza melodia and Swamp Sparrow Melospiza georgiana) raised in a controlled auditory environment from the egg (these birds cannot hear before hatching) and given equal exposure to songs from both species, had a bias towards learning own species song. He also showed that this was unlikely to be due to differential ability of the two species to produce each other's sounds. Marler proposed that young animals are born with a kind of crude «template or schema» that directs their attention to sounds with some of the general characteristics of species sounds; such «interesting» sounds would be committed to memory and used as models to guide the bird's own vocal development. In my own doctoral work (Balaban 1988a,b,c), I found that female Swamp Sparrows were more sexually interested in songs that had general organizational features characteristic of the population they were born into, independent of the songs they experienced while growing up. What kind of developmental brain process could explain how an organism knows what it wants to learn about in advance of ever being exposed to it?

At this time the predominant explanations for such abilities revolved around special brain systems dedicated exclusively to particular kinds of stimuli from birth (akin to genetically-specified "grandmother cells", the somewhat facetious name given to neurons presumably tuned to highly specific, complex features like a particular person's grandmother). While Marler's results could be interpreted in a variety of ways, they did produce an interesting alternative hypothesis. Neural processes that control a young animal's attention, when operating in early development alongside relatively «unspecialized» perceptual, learning and memory processes (that could be mechanistically similar among different species), might result in substantial differences in adult brain function (and behavior) in members of different species with generally similar brains. Evolved specializations attached to more «global» circuitry that modulates attention could thus play a major 
role in sculpting «local» circuit differences via individual experience during development.

A developmental model of this type mitigates the kind of arguments that still polarize the human speech community, which continues to debate the extent to which speech sounds are processed by «specialized and dedicated» circuits in the human brain (Lotto et al., 1997). For instance, while other animals do not appear spontaneously motivated to learn about speech contrasts in a detailed fashion, they can be motivated to do so by a food reward. Under such conditions, animals can be trained to distinguish any human speech contrast and seem to do so in a similar way to human listeners. Since the auditory neural circuits of all vertebrates appear to exhibit a high degree of plasticity, an explanation proposing that humans have something in their brain that causes infants to spontaneously pay attention to and memorize speech sounds, but otherwise have auditory processing circuitry similar to that of other primates would appear to have some merit. Explanations based on these sorts of predispositions are attracting increasing attention from evolutionary biologists (Stamps 2003), as well as human developmental psychologists (Morton \& Johnson 1991, Johnson 1997). The time appeared to be ripe to collect factual information about the actual neural mechanisms by which predispositions operate.

First, we needed an objective method of operationally defining and studying a predisposition. In work initially started in Nogent together with Thomas Park, chick and quail eggs were incubated in isolation from all adult vocalizations. Shortly after hatching, auditory preferences of individuals were tested repeatedly by giving each animal simultaneous and equal exposure to calls from the two species that differed in biological significance, resulting in a different behavioral outcome being directed toward the two calls. We took advantage of a naturally occurring behavioral pattern in chicks and quail - the young birds are able to walk within hours of hatching; during the first weeks of life, young learn to forage for food and are closely monitored by their parents. When there is danger nearby a special «maternal call» is given by the parents; the young respond by immediately rushing to the calling source. Chicken and quail maternal calls are acoustically distinct from each other and the young of both species do not produce any vocalization acoustically similar to parental maternal calls (Guyomarc'h 1962, 1966,_1974). Young are simultaneously and equally exposed to the calls of both species. The "significant» stimulus for one species serves as the "control» stimulus for the other species. Auditory predispositions are inferred from behavioral approach performance; a predisposition is said to exist if individual members of each species exhibit robust approach preferences for own-species stimuli with respect to the simultaneously presented calls from the other species (Park \& Balaban 1991).

In spite of the fact that subjects had equal exposure to the calls of both species at all times, the young of both species were highly biased in their responsiveness, being much more likely to spend time vigorously trying to approach the maternal call of their own species. The auditory preferences exhibited substantial interindividual variability within each species. Species members either preferentially approach the call of their own species with varying regularity (the majority of individuals), or show no preference (a minority of individuals). No individuals had a significant tendency to preferentially approach the maternal calls of the other species. The mean population preference did not change as a function of age or experience with the calls in either species. It is important to note that data collection in these preference experiments was completely automated, as was the calculation of the measure of preference, so that no potential for observer bias or subjectivity is involved in the derivation of auditory preference behavior.

Together with Kevin Long and Grace Kennedy, we surveyed the entire brain from the rostral telencephalon to the caudal brainstem in a search for regions that, when transplanted from quail to chicks, would transform the auditory preference behavior of chimeric individuals (Long etal., 2001). The major results of this study were: (1) the transfer of responses from significantly chickencall directed to significantly quail-call-directed was specifically associated with the transplant of a bilaterally-delimited region of the rostral mesencephalon / caudolateral diencephalon. All subjects containing transplants of this region exhibited quail-like call approach behavior. This region does not appear to include any currently-known avian primary auditory regions in the classical pathways leading from the brainstem to the thalamus and telencephalon; (2) the transfer of this abstract aspect of auditory perception was dissociated from changes to the vocalizations of chimeric animals, making it unlikely that experiential differences based on auditory self-stimulation (Gottlieb, 1997) can account for these results; and (3) chimeras containing the behaviorallyeffective transplant region had, as a group, auditory approach preference scores that were significantly more skewed toward extreme «quail» values than the population of unoperated quail. This last result is of special note, for it potentially indicates some interesting developmental dynamic changes resulting from the substitution of quail for chicken cells in this circuit that may be related to known differences in the rate of phenotypic maturation of chicken and quail cells.

\section{Current work and future directions}

Currently, my colleagues and I are trying to better localize the bilateral region responsible for transforming this perceptual predisposition and trying to understand the more global neural circuit(s) it participates in so that we can initiate detailed studies of what this region does in development and the mechanism through which transplants change its functioning. We have begun studies examining this circuitry using differences in sound induced immediate-early gene (IEG) expression at one day after hatching (Long et al., 2002) and are exploring the use of PET and fMRI imaging for examining sound-induced circuit activity. We are also exploring the developmental origin of differential activity induced in particular regions by chick and quail sounds at one-day posthatching by studying sound-induced and spontaneous IEG expression in these areas (the latter as an index of intrinsicallygenerated circuit activity) in developing embryos of normal and chimeric animals at earlier and earlier ages. Finally, we are seeking to apply this technique to the perceptual biases of songbirds during song learning to see if these lie in homologous brain regions (and proceed via similar neural mechanisms) to this initial example studied in chicks and quail.

It is our hope that by understanding more about the internal structure and connectivity of the region that transforms auditory approach behavior, as well as the more global circuit(s) that it is a part of, we can understand the way that perceptual predispositions are built into brains, how they may serve to organize response 
features of other brain regions during development and how evolutionary changes in their function are manifest.

\section{Reflections on becoming a brain switcher}

Nogent served as an extremely potent incubator for my scientific and personal development. I'll always be grateful to Nicole Le Douarin for her gracious hospitality and for teaching me the value of scientific courage, infectious and supportive enthusiasm and the art of using deceptively simple experimental manipulations to reveal the sophisticated workings of complex and dynamic developmental systems. It was a privilege to interact so closely with like-minded people from all over the world who had such a great diversity of scientific and social interests. The best gifts we can bestow on others are the subtle inductions that (not necessarily immediately) cause hidden features to become expressed and cause us to realize unimagined potentialities. Like early development, part of the credit goes to the locale, part to the inducers and part to the latent potentialities of those experiencing the induction. I only hope that I induced in my friends and colleagues at Nogent some small fraction of what was induced in me and that we all continue these inductions with our students, colleagues and each other well into the future.

\section{References}

BALABAN, E. (1988a) Bird song syntax: learned intraspecific variation is meaningful. Proc. Natl. Acad. Sci. USA 85: 3657-3660.

BALABAN, E. (1988b) Cultural and genetic variation in Swamp Sparrows (Melospiza georgiana): I. Song variation, genetic variation and their relationship. Behaviour 105: 250-291.

BALABAN, E. (1988c) Cultural and genetic variation in Swamp Sparrows (Melospiza georgiana): II. Behavioral salience of geographic song variants. Behaviour 105: 292-322.

BALABAN, E. (1990) Avian brain chimeras as a tool for studying species behavioral differences. In The Avian Model in Developmental Biology: From Organism to Genes, (Ed. N.M. Le Douarin, F. Dieterlen-Lièvre and J. Smith). CNRS Press, Paris, pp. 105-118.

BALABAN, E. (1997) Changes in multiple brain regions underlie species differences in a complex, congenital behavior. Proc. Natl. Acad. Sci. USA 94: 2001 - 2006.

BALABAN, E., TEILLET, M.A. and LE DOUARIN, N.M. (1988) Application of the quail-chick chimera system to the study of brain development and behavior. Science 241: 1339-1342

BATINI, C., TEILLET M.A., NAQUET R. and LE DOUARIN, N.M. (1996) Brain chimeras in birds: application to the study of a genetic form of reflex epilepsy. Trends Neurosci. 19: 246-52.

BATINI, C., TEILLET M.A. AND NAQUET R. (2004) An avian model of genetic reflex epilepsy. Archives Italiennes de Biologie 142: 297-312.

FADLALLAH N., GUY N., TEILLET M.A., SCHULER B., LE DOUARIN N.M., NAQUET R. and BATINI C. (1995) Brain chimeras for the study of an avian model of genetic epilepsy: structures involved in sound and light-induced seizures. Brain Res. 675: 55-66.

GAHR M. (2003) Male Japanese quails with female brains do not show male sexual behaviors. Proc. Natl. Acad. Sci. USA 100: 7959-7964.

GAHR M. and BALABAN, E. (1996) The development of a species difference in the local distribution of brain estrogen receptive cells. Developmenta/Brain Research 92: $182-189$.

GOTTLIEB, G. (1997) Synthesizing nature- nurture: The prenatalroots of instinctive behavior. Lawrence Erlbaum Associates, Mahwah, NJ.

GUY N.T., FADLALLAH N., NAQUET R. and BATINI C. (1995) Development of epileptic activity in embryos and newly hatched chicks of the Fayoumi mutant chicken. Epilepsia 36: 101-107.
GUYOMARC'H, J.-C. (1962). Contribution à l'étude du comportement vocal du poussin de Gallus domesticus. Journale de Psychologie Normale et Pathologique 3: $283-305$.

GUYOMARC'H, J.-C. (1966) Les émissions sonores du poussin domestique, leur place dans le comportement normal. Zeitschrift für Tierpsychologie 23: 141160.

GUYOMARC'H, J.-C. (1974) Les vocalizations des Gallinaces: Structure des sons et des repertoires, Ontogenèse motrice, et acquisition de leur Semantique, Vol. / et II. Thèse d'Etat, Université de Rennes: Rennes.

HEATON, M.B. (1973) Xenoplastic eye transplantation between chick and quail embryos: Some neuroanatomical and functional aspects. J. Comp. Neurol. 151: 359-376.

JOHNSON, M. H. (1997) Developmental cognitive psychology. Blackwell, Oxford.

KATZ, P.S. and HARRIS-WARRICK, R.M. (1999) The evolution of neuronal circuits underlying species-specific behavior. Curr. Opin. Neurobiol. 9: 628-633.

LE DOUARIN, N.M. (1969) Particularitités du noyau interphasique chez la caille japonaise. Utalisation de ces particularités comme 'marque biologique' dans le recherches sur les interactions tissulaires et les migrations au cours de l'ontogenèse. Bulletin Biologique de la France et de la Belgique 103: 435-452.

LEDOUARIN, N.M. (1982) The neuralcrest. Cambridge University Press, Cambridge.

LE DOUARIN, N.M. (1986) Cell line segregation during peripheral nervous system ontogeny. Science 231: 1515-1522.

LE DOUARIN, N.M. (1988) Embryonic chimeras as a tool for studying the development of the nervous and immune systems. Proc. Royal Acad. Sci. (London), Series B 235: 1-17.

LE DOUARIN, N.M., CATALA, M. and BATINI, C. (1997) Embryonic neural chimeras in the study of vertebrate brain and head development. Int. Rev. Cytol. 175: 241-309.

LE DOUARIN, N.M., DIETERLEN-LIEVRE, F., TEILLET, M.A. and ZILLER, C (2000) Interspecific chimeras in avian embryos. Methods Molec. Biol. 135: 37386.

LE DOUARIN, N.M. and KALCHEIM, C. (1999) The neural crest. $2^{\text {nd }}$ edition. Cambridge University Press, Cambridge.

LE DOUARIN, N.M., TEILLET, M. and FONTAINE-PERUS, J. (1984) Chimeras in the study of the peripheral nervous system of birds. In Chimeras in Developmental Biology (Ed. N.M. Le Douarin and A. McLaren). Academic Press, New York, pp. 313-352.

LONG, K.D., KENNEDY, G. and BALABAN, E. (2001) Transferring an inborn auditory perceptual predisposition with interspecies brain transplants. Proc. Natl. Acad. Sci. USA 98: 5862-5867.

LONG, K.D., KENNEDY, G., SALBAUM, M. and BALABAN, E. (2002) Auditory stimulus-induced changes in immediate-early gene expression related to an inborn perceptual predisposition. J. Comp. Physiol. Series A 188: 25-38.

LOTTO, A.J., KLUENDER, K.R. and HOLT L.L. (1997) Animal models of speech perception phenomena. In Chicago Linguistic Society, Volume 33 (Ed. K. Singer, R. Eggert and G. Anderson). Chicago Linguistic Society, Chicago, pp. 357-367.

MARLER, P. (1984) Song learning: innate species differences in the learning process. In The biology of learning (Ed. P. Marler and H. Terrace). SpringerVerlag, Berlin, pp. 289 - 309.

MARLER, P. (1990) Innate learning preferences: signals for communication. Developmental Psychobiology 23: 557 - 568.

MARLER, P. (1997) Three models of song learning: evidence from behavior. J. Neurobiol. 33: 501 - 516.

MARLER, P., DOOLING, R. J. and ZOLOTH, S. (1980) Comparative perspectives on ethology and behavioral development. In Comparative methods in psychology (Ed. M. H. Bornstein). Lawrence Erlbaum Associates: Mahwah, NJ, pp. 189 - 230.

MARLER, P. and PETERS, S. (1977) Selective vocal learning in a sparrow. Science 198: 1393 - 1396.

MARTINOVICH, P.N. (1957) Transplantation of the embryonic chick forebrain region before establishment of circulation. Proc. Natt. Acad. Sci USA 43: 354-356.

MARTINOVICH, P.N. (1958). Transplantation of the forebrain region in bird embryos before establishment of circulation: Heteroplastic transplants. Nature 182: 572 , 589. 
MARTINOVICH, P. N. and PAVLOVIC, M. (1958) Transplantation of the forebrain region in bird embryos before establishment of circulation: Homoplastic transplants. Nature 182: 571-572.

MARTINOVICH, P. N. (1959) The transplantation of the forebrain region in bird embryos before the establishment of a circulation and some of the problems involved. J. Exp. Zool. 142: 571-85.

MORTON, J. and JOHNSON, M. H. (1991) CONSPEC and CONLERN: a twoprocess theory of infant face recognition. Psychological Rev. 98: 164-181.

PARK, T. and BALABAN, E. (1991). Relative salience of species maternal calls in neonatal Gallinaceous birds: A direct comparison of Japanese quail (Coturnix coturnix japonica) and domestic chickens (Gallus gallus domesticus). J. Comp. Psychol 105: 45-54.

PIETSCH, P. (1972a) Scrambled salamander brains: A test of holographic theories of neural program storage. Anat. Record 172: 383-384.

PIETSCH, P. (1972b) Shuffle brain. Harper's Magazine 244: 1464.

PIETSCH, P. (1981) Shufflebrain. Houghton Mifflin, Boston.

SENO, T. and SAITO, S. (1959) A chimaeric duck with the head of a chick. Nature 184: B.A. 78-79.
SHAW, B. (1999) Involvement of a midbrain vocal nucleus in the production of both the acoustic and postural components of crowing behavior in Japanese quail. J. Comp. Physiol. Series A 186: 747-757.

SHAW, B. and KENNEDY, G. (2002) Evidence for species differences in the pattern of androgen receptor distribution in relation to species differences in an androgendependent behavior. J. Neurobiol. 52: 203-220.

SOHAL, G. S. (1976) Effects of reciprocal forebrain transplantation on motility and hatching in chick and duck embryos. Brain Res. 113: 35-43.

STAMPS, J. (2003) Behavioral processes affecting development: Tinbergen's fourth question comes of age. Animal Behav. 66: 1-13.

TEILLET, M.A., GUY, N.T., SCHULER, B., LE GAL LA SALLE, G., BATINI, C., LE DOUARIN, N.M. and NAQUET, R. (1993) Transfer of a genetic form of epilepsy in the chicken by embryonic brain grafts. Comptes Rendus de la Academie des Sciences ///316:1164-76.

TEILLET, M.A., GUY, N., FADLALLAH, N., LE GAL LA SALLE, G., SCHULER, B., BATINI, C., LE DOUARIN, N. and NAQUET, R. (1995) Reflex epilepsy of the fowl and its transfer to normal chickens by brain embryonic grafts. Italian Journal of Neurological Science 16: 83-89.

TEILLET, M.A., ZILLER, C. and LE DOUARIN, N.M. (1999) Quail-chick chimeras. Methods Molec. Biol. 97: 305-18. 